\title{
Pregnancy and Childbirth from Maternal Health Perspective
}

\author{
Kamal Gautam and Ishara Mahat* \\ Faculty of Education, Tribhuvan University, Kirtipur, Nepal, India \\ University of Ottawa, School of Sociology and Anthropology of Development, Canada
}

Submission: September 10, 2018; Published: September 26, 2018

*Corresponding author: Ishara Mahat, University of Ottawa, School of Sociology and Anthropology of Development, Canada, Email: imahat@uottawa.ca

\begin{abstract}
Every pregnancy has some risk of problem during pregnancy and child birth. These problems range from simple to more complicated and even death of mother and child. Problem of vaginal bleeding, infection, swelling of legs, vomiting tendency and morning sickness, loss of appetite, problems in sleep are some common health problems. Likewise, high blood pressure, unsafe abortion, and obstructed labor, mental depression, diabetes during pregnancy and cardiovascular diseases are the complicated health problems. A descriptive study on pregnancy and health was carried out at Khidim gaunpalika of Arghakhanchi district in March 2017. Main objective of this study was to identify health problems in female during their pregnancy. Mothers who attended antenatal visit to local health post were taken as the respondents. The study included 76 antenatal cases in total with purposive sampling method. Interview as a tool was applied for data collection and descriptive analysis was done.
\end{abstract}

Keywords: Motherhood; Antenatal; Disease; Morbidity; Health problems; Health service

Abbreviations: AHW: Auxiliary Health Worker; MCHW: Maternal and Child Health Worker; VHW: Village Health Worker; FCHV: Female Community Health Volunteers

\section{Background}

The birth of a child is a welcome event in almost all ethnic groups, castes and regions of Nepal. People invest significant amount to celebrate child birth in every society. Some of the family invites to take feast in their house on the celebration of child birth. Married couples of any regions of Nepal are expected to have children as it is wanting of the women of any countries. A childless/barren couple is looked down on and is considered unfortunate. A childless or barren couple is seen a symbol of unfortunate in Nepal. Motherhood is taken as a positive and fulfilling experience for too many women, it is associated with suffering, ill-health and even death. The major direct causes of maternal morbidity and mortality include haemorrhage, infection, high blood pressure, unsafe abortion, and obstructed labor. Despite the significant reduction in maternal mortality, every day about 830 women still die during pregnancy and childbirth. The majority (99\%) of these deaths occur in developing countries [1].

Most women do not have access to the health care and sexual health education services which they need. In many developing countries, complications of pregnancy and childbirth (mainly at the level of preconception and prenatal care) are the leading causes of death among women of reproductive age. Gnawali [2] states that only $10 \%$ people receive antenatal service in rural areas in Nepal and only $17.6 \%$ women are brought to health institutions for delivery. The report also shows that only $2.3 \%$ women receive postnatal care services from health post in rural areas. The report of Nepal Health Demographic Survey states that just over one-third (36\%) of women nation-wide have access to skilled birth attendants (source).

It is claimed that the level of training of health workers attending deliveries in remote areas of Nepal falls far short of the international standard for midwifery. The report further says that the maternal mortality ratio (maternal deaths) in Nepal has gradually declined over the past two decades; however, it is still very high in remote rural pockets [3]. The gradual decline in the maternal mortality ratio has resulted in suicide becoming more obviously visible in the statistics. Another study states that nearly $16 \%$ of the maternal deaths were due to indirect cause, where suicide or homicide were the major reasons for almost all deaths.

The government of Nepal has been implementing a free delivery policy since 2009 , providing incentives to women who choose to deliver in a designated health facility [4]. However, the country continues to have a high MMR (229 per 100000 live births) with underutilization of maternal health services one of the reasons contributing to this high maternal death rate in Nepal [5]. Recently, a nationwide survey showed that about 6 in 10 pregnant women received antenatal care (ANC) from skilled 
providers, while only $35 \%$ of childbirths occurred in health institutions [6].

\section{Methodology}

i. Study Design: a descriptive research design was applied in this study. However, the focus was on the antenatal and natal care along with the health problems faced by the respondents during antenatal period.

ii. Study Population: for this purpose, antenatal cases who attended antenatal visit to local health post were chosen as the respondents. For natal care, required data was taken from health post record. All mothers who attended in local health post were the population of the study.

iii. Sources of Data: for this purpose, both primary and secondary sources of data were used. Interview was taken with the pregnant mothers and health post staff as primary source and out -patient record register maintained by health post was checked for delivered mothers.

iv. Study tool: Interview schedule and observation checklist were the tool used for data collection.

v. Data collection and analysis procedures: all the pregnant women who came to health post within a week for antenatal check- up were taken with census method. For natal cases, record of OPD for the last six months was checked and even interview was taken with the health post in-charge. For analysis purpose, thematic analysis method was applied.

Results

\section{Socio Demographic Profile}

Among antenatal mothers, out of 76 responds, 24 were from Brahman and Chhetris, 28 from Janjatis, 14 from dalits and rest from marginal groups. The age of respondents seemed varied from 17 years to 37 years of age. Regarding occupation, 09 were the job holders, 03 were belonged to business and rest were the housewives. However, the health post record showed that there were 26 cases who came for delivery at health post. Among those who came for delivery, 16 were from Brahmin and Chhetri, 5 from janjati and 5 from minorities and dalit community. Among them, 22 were the cases of first-time delivery. However, health post source told that some cases might have gone to hospitals for delivery as health post lacked modern facility to handle complications at local level.

\section{Description of the Visit}

Out of the total respondents, 32 were the new cases who had visited health post for the first time after pregnancy. Among others, 29 had visited second time, 13 had visited third and only two were found at their fourth visits to health post. As mentioned earlier, there were only 26 cases were registered for safe delivery allowance that is given to mothers who get delivered at health post.

\section{Minor Health Problems}

Table 1: Minor health problems during pregnancy.

\begin{tabular}{|c|c|}
\hline Description & Percentage \\
\hline Cases with no health problems & 23.68 \\
\hline Cramps & 2.63 \\
\hline Back pain and burning Urinary tract & 6.57 \\
\hline Heartburn and indigestion & 17.1 \\
\hline Loss of appetite & 5.26 \\
\hline Headache and allergy & 9.21 \\
\hline Others. Swelling of vein, Anaemia & 6.57 \\
\hline
\end{tabular}

The cases as mentioned in Table 1 show different minor health problems in pregnancy period. According to Table, 18 cases were found having no health problem at all. Among others 2 cases had cramps, 5 had burning urinary tract followed by backache, and 13 had heartburn and indigestion problems. Likewise, a symptom of low appetite seemed to be expressed by 4 cases. Headache and allergy seemed to be reported by 7 cases. Complain of back pain, varicose veins and constipation was found in 5 respondents. However, no major complications during child birth were found recorded.

\section{Major Health Problems}

Among the cases, 3 were found having bleeding and other complications in few months ago but at the time of interview they were completely cured. There were just coming for followup visit. However, health post record showed that there were 7 complicated cases with excessive bleeding, preeclampsia, and mental depression. They were sent to nearby hospitals for further investigation. One case had been referred to hospital due to septic abortion that according to health post source was suspected to be handled by non- health personnel at home. However, no death was reported among antenatal and post-natal mothers during study period.

\section{Trends of Visit}

The record book maintained by health post showed gradual improvement in number of antenatal cases visited to health post in last six months. There were 132 total cases visited in last five months and 76 were noticed in the week of study. The health post was found equipped somehow with modern facilities but still lacked diagnostic equipment. Likewise, postnatal cases were increased significantly in later three months. There were 17 delivery cases in record in the first three-month period which in the later three months reached to 26 cases.

\section{Discussion}

Antenatal care is the very first stage of maternal care and deals with the care of mother during pregnancy. Appropriate antenatal service promotes safe motherhood and delivery with improved maternal and neonatal outcomes. It often presents the first contact opportunities for a pregnant woman to connect with health services, thus offering an entry point for integrated care, 
promoting healthy home practices, influencing care-seeking behaviors and linking women with pregnancy complications to a referral system, thus impacting positively on maternal and fetal health [7].

Along with several factors, family role is seen as one of the determinant factors for less utilization of antenatal visits in Nepal. In the context of Nepal, fifty-eight percent of mothers receive antenatal care from a skilled provider (a doctor, nurse, or midwife) for their most recent births. In addition, 26 percent of mothers receive antenatal care from trained health workers such as a health assistant or auxiliary health worker (AHW), a maternal and child health worker (MCHW), or a village health worker (VHW). Less than 1 percent of women receive antenatal care from a Female Community Health Volunteers (FCHV). Fifteen percent of women receive no antenatal care for births [8].

Still people of rural community of Nepal perceive health facility at community level less important to them. Inadequate perception leads them to less utilization of health services. In Nepal according to a research report of Jumla, Salyan and Pyuthan conducted by Gnawali [2] only $68.1 \%$ male of reproductive age receive condom from health post. The report shows poor practice of antenatal visit in rural areas stating that only $10 \%$ people receive antenatal service in such areas and only $17.6 \%$ women are brought to health institutions for delivery. The report also shows that still about $82 \%$ deliveries in rural areas are conducted at home and only $2.3 \%$ women receive postnatal care services from health post. Thapa [9] also shows the evidence of less utilization of different cares. According to him, the overall coverage of antenatal care, delivery and post-natal care services is $42.7 \%, 15.0 \%$ and $14.4 \%$, accordingly. Dhakal [10] state that women are influenced by their mother- in law on whether to use antenatal service. They further mention that younger women and those with secondary education are more likely to have used antenatal care.

\section{Conclusion}

Antenatal care has been recognized to improve health outcomes for pregnant women and their babies. However, significant numbers of pregnant women in Nepalese context do not receive the recommended four antenatal visits. Despite the huge investment in health service delivery system by the Nepalese government and many other development agencies, quality health service is still to be desired. Present health service delivery system of health posts and sub-health posts in rural areas is inadequate in terms of available facilities and diagnostic resources. Health services also lack adequate number of staff and drugs.

\section{References}

1. World Health Organization (2015) Maternal mortality: factsheet. Geneva, Switzerland, Europe.

2. Silwal M (2011) Maternal health care practices among indigenous people of Nepal: A case study of the Raute Community. Master of Philosophy in Indigenous Studies. Faculty of Humanities, Social Sciences and Education University of Tromsø, Norway.

3. Bogren M, van Teijlingen E, Berg M (2013) Where midwives are nsot yet recognized: A feasibility study of professional midwives in Nepal, Midwifery, India.

4. Karkee R (2013) Determinants of facility delivery after implementation of safer mother programme in Nepal: a prospective cohort study. BMC Pregnancy Childbirth 13: 193.

5. Gill k (2013) Determinants of facility delivery after implementation of safer mother programmed in Nepal: a prospective cohort study. BMC Pregnancy Childbirth 13: 193.

6. MoHP (2011) Nepal demographic and health survey. Ministry of Health \& Population, Kathmandu, Nepal, India.

7. Bulatoo R (2000) Rating maternal and neonatal health programs in developing countries. Chapel Hill, MEASURE Evaluation Project, University of North Carolina, Carolina Population Centre, USA.

8. Population Division/MoHP and New Era, MOHP (2011) Nepal Demographic Health Survey. Population Division/MoHP \& New Era: Kathmandu, Nepal, India.

9. Thapa K (2011) Sexual violence among Magar adolescent girls in Nepal. A Dissertation Submitted to Faculty of Education, TU for the degree of Doctor of Philosophy in Education (Health Education).

10. Dhakal S (2011) Antenatal and postnatal cares among rural women in Nepal: A community-based study. A study report submitted to the Department of Public Health, University of Aberdeen, UK.

\section{Your next submission with Juniper Publishers will reach you the below assets}

- Quality Editorial service

- Swift Peer Review

- Reprints availability

- E-prints Service

- Manuscript Podcast for convenient understanding

- Global attainment for your research

- Manuscript accessibility in different formats

( Pdf, E-pub, Full Text, Audio)

- Unceasing customer service

Track the below URL for one-step submission

https://juniperpublishers.com/online-submission.php 